\title{
EVALUASI PENCATATAN KOHORT BAYI DI WILAYAH KABUPATEN PEKALONGAN
}

The Evaluation Recording of Baby's Cohort ini the region of Pekalongan

\author{
Rini Kristiyanti ${ }^{1}$, Pujiati Setyaningsih ${ }^{2}$, Nuniek Nizmah Fajriyah ${ }^{3}$ \\ STIKES Muhammadiyah Pekajangan Pekalongan \\ (mamabilgis@gmail.com)
}

\begin{abstract}
ABSTRAK
Latar belakang: Keberhasilan upaya pelayanan kesehatan pada bayi dapat diketahui melalui cakupan pelayanan kesehatan bayi, yang didalamnya menggambarkan kinerja bidan dalam memberikan pelayanan kepada bayi. Kohort bayi merupakan salah satu instrumen kesehatan ibu dan anak yang merupakan sumber data tentang bayi di suatu wilayah kerja bidan. Evaluasi pencatatan kohort perlu dilakukan agar dapat mengetahui sejauh mana instrumen tersebut bermanfaat dan untuk menentukan program ke depan berkaitan dengan kesehatan ibu dan anak.

Tujuan: Menggambarkan evaluasi pencatatan kohort bayi di wilayah Kabupaten Pekalongan.

Metode: Penelitian ini merupakan penelitian deskriptif dengan pendekatan cross sectional. Populasi penelitian ini adalah seluruh bidan di wilayah kabupaten Pekalongan sejumlah 339 orang. Teknik pengambilan sampel dengan menggunakan purposive sampling didapatkan 6 puskesmas dengan subyek penelitian sejumlah 57 orang. Pada penelitian ini menggunakan checklist yang diisi sesuai dengan hasil kohort bayi masing-masing subyek penelitian. Analisa data menggunakan analisis univariat.

Hasil: Item dalam kohort bayi diisi dengan lengkap sebesar 16,7\% (No.urut, nama bayi, jenis kelamin, jenis kelamin, alamat, dan kondisi saat lahir), sedangkan item yang lain diisi tidak lengkap. Hasil tidak lengkap paling sering ditemui pada item NIK (93\%), kematian $(98,2 \%)$, masuk balita $(75,4 \%)$, dan keterangan $(82,5 \%)$
\end{abstract}

Simpulan: Sebagian besar $(83,3 \%)$ item dalam kohort bayi belum diisi dengan lengkap oleh bidan

Kata kunci: pencatatan, kohort bayi

\section{ABSTRACT}

Background: The success of health care efforts in infants can be identified through the coverage of infant health services, which in it describes the performance of midwives in providing services to infants. Baby cohort is one of the maternal and child health instruments which is a source of data about infants in a midwife's work area. Evaluation of cohort recording needs to be done in 
order to find out the extent to which the instrument is useful and to determine future programs related to maternal and child health.

The Aim: To describe the evaluation of the recording of infant cohorts in Pekalongan Regency.

Method: This study is a descriptive study with a cross sectional approach. The study population was 339 people in the Pekalongan district area. The sampling technique using purposive sampling found 6 puskesmas with 57 research subjects. In this study using a checklist filled in according to the results of the baby cohort of each research subject. Data analysis using univariate analysis.

Results: Items in the infant cohort were complete filled with a total of $16.7 \%$ (Number of order, baby's name, gender, gender, address, and condition at birth), while other items were filled in incompletely. Incomplete results are most often found in NIK items (93\%), deaths (98.2\%), entry in toddlers $(75.4 \%)$, and information $(82.5 \%)$

Conclusion: Most (83.3\%) items in the baby cohort have not been filled in completely by the midwife.

Keywords: recording, infant cohort

\section{PENDAHULUAN}

Angka kematian bayi (AKB) di Indonesia berdasarkan hasil survey demografi dan kesehatan Indonesia (SDKI) pada tahun 2012 sebesar 32/1.000 kelahiran hidup dan angka kematian neonatal (AKN) sebesar 19/1.000 kelahiran hidup. Selain AKB dan AKN, Indonesian juga mengalami tingginya angka kematian balita yaitu 40/1.000 kelahiran hidup. (Profil Kesehatan Indonesia, 2014).

Penyebab AKB antara lain diare (31,4\%), pneumeoni (23,8\%), meningitis $(9,3 \%)$, kelainan saluran pencernaan $(6,4 \%)$, kelainan jantung dan hydrocephalus $(5,8 \%)$, sepsis $(4,1 \%)$, tetanus $(2,9 \%)$, malnutrisi $(2,3 \%)$, TB $(2 \%)$, lain-lain $(2 \%)$. Adapun penyebab kematian bayi yang paling sering pada usia (1-11 bulan) adalah diare, pneumonia dan meningitis, sedangkan pada bayi usia (0-1 bulan) adalah sepsis, kelainan kongenetal dan pneumonia. (Kemenkes, 2007).

Komplikasi yang menjadi penyebab kematian terbanyak antara lain asfiksia, bayi berat lahir rendah (BBLR) serta infeksi. Komplikasi ini dapat dicegah dan ditangani, namun terkendala oleh akses ke pelayanan kesehatan, kemampuan tenaga kesehatan, keadaan social ekonomi, sistem rujukan yang belum berjalan dengan baik, terlambatnya deteksi dini, serta kesadaran orang tua untuk mencari pertolongan kesehatan. (Profil Kesehatan Indonesia Tahun 2014).

Upaya untuk menangani permasalahan tersebut pemerintah mengadakan program pelayanan kesehatan pada bayi. Pelayanan ini terdiri dari penimbangan berat badan, pemberian imunisasi dasar, stimulasi deteksi intervensi dini tumbuh kembang (SDIDTK) bayi, pemberian vitamin A pada bayi, penyuluhan perawatan kesehatan bayi, penyuluhan ASI eksklusif dan pemberian makanan pendamping ASI (MP-ASI). (Profil Kesehatan Indonesia Tahun 2014). 
Keberhasilan upaya pelayanan kesehatan pada bayi dapat diketahui melalui cakupan pelayanan kesehatan bayi, yang didalamnya menggambarkan kinerja bidan dalam memberikan pelayanan kepada bayi. Agar hasil pelayanan kesehatan pada bayi dapat dievaluasi secara terarah dilakukan melalui suatu pencatatan dan pelaporan.

Pencatatan adalah kegiatan atau proses pendokumentasian suatu aktivitas. Bentuk catatan dapat berupa tulisan, grafik, gambar, dan suara kemudian diakhiri dengan pembuatan laporan. Pelaporan adalah catatan yang memberikan informasi tentang kegiatan tertentu (Syahlan, 1996).

Untuk mengatasi permasalahan di atas, maka pelayanan kesehatan antenatal di Fasilitas Kesehatan pemerintah maupun swasta dan praktik perorangan/ kelompok perlu dilaksanakan secara komprehensif dan terpadu, mencakup upaya promotif, preventif, kuratif sekaligus rehabilitatif (Kemenkes RI, 2013). Untuk mendukung upaya promotif dan preventif, maka Kementrian Kesehatan telah mengeluarkan berbagai instrumen Kesehatan Ibu dan Anak, meliputi Kohort Ibu, Kohort Anak, Kohort Balita, Kartu Ibu, Buku Kesehatan Ibu dan Anak (KIA), Manajemen Terpadu Balita Muda (MTBM) dan program Antenatal Care (ANC) terpadu.

Terdapat 27 puskesmas di wilayah kerja Dinas Kesehatan Kabupaten Pekalongan dengan jumlah bidan yang bertugas di Puskesmas wilayah Kabupaten Pekalongan sejumlah 339 orang. Terkait dengan pencatatan instrumen KIA yang dilakukan oleh bidan masih didapatkan kendala antara lain kelengkapan dan ketepatan dalam pelaporan yang dapat berdampak pada pelaporan di tingkat Kabupaten. Diperlukan evaluasi yang merata, proporsional dan seimbang mengenai pemanfaatan insturmen KIA sehingga didapatkan gambaran nyata kondisi pelayanan di fasilitas kesehatan pemerintah di Kabupaten Pekalongan. Instrumen-insturmen tersebut sudah didistribusikan ke fasilitas pelayanan kesehatan pemerintah di Kabupaten Pekalongan, akan tetapi sampai saat ini belum pernah dilakukan evaluasi terhadap pemanfaatan instrumen tersebut. Melalui proses evaluasi akan dapat diperoleh gambaran sejauh mana instrumen kesehatan ibu dan anak digunakan, sejauh mana instrumen tersebut bermanfaat dan untuk menentukan program ke depan sehingga lebih sesuai dengan kondisi yang nyata terjadi di pelayan kesehatan dasar di Wilayah kerja Dinas Kesehatan Kabupaten Pekalongan (Dinkes Kab.Pekalongan, 2016).

Berdasarkan uraian di atas penulis tertarik meneliti evaluasi pencatatan kohort bayi di wilayah Kabupaten Pekalongan supaya mendapatkan gambaran nyata pemanfaatan instrumen kohort bayi oleh bidan di wilayah Kabupaten Pekalongan

\section{METODE PENELITIAN}

Penelitian ini merupakan penelitian deskriptif kuantitatif dengan pendekatan cross sectional. Populasi penelitian ini adalah seluruh bidan di wilayah kabupaten Pekalongan sejumlah 339 orang. Teknik pengambilan sampel dengan menggunakan purposive sampling diambil 20\% dari 27 puskesmas, didapatkan 6 Puskesmas, yaitu Doro 2, Kajen 2, Kedungwuni 2, Karangdadap, Tirto 1, dan 
Wiradesa, dengan subyek penelitian sejumlah 57 orang. Pada penelitian ini menggunakan checklist yang diisi sesuai dengan hasil observasi pencatatan kohort bayi masing-masing subyek penelitian, dimana hasil lengkap apabila item diisi benar dan lengkap, kurang lengkap apabila item diisi benar ataupun tidak benar dan tidak lengkap, serta apabila item tidak diisi sama sekali. Analisa data menggunakan analisis univariat.

\section{HASIL DAN PEMBAHASAN}

Tabel 1 Distribusi frekuensi responden berdasarkan pencatatan kohort bayi

\begin{tabular}{|c|c|c|c|c|c|c|}
\hline & Lengkap & $\%$ & $\begin{array}{l}\text { Kurang } \\
\text { lengkap }\end{array}$ & $\%$ & $\begin{array}{c}\text { Tidak } \\
\text { lengkap }\end{array}$ & $\%$ \\
\hline No urut & 57 & 100 & 0 & 0,0 & 0 & 0,0 \\
\hline NIK & 2 & 3,5 & 2 & 3,5 & 53 & 93,0 \\
\hline Nama bayi & 57 & 100 & 0 & 0,0 & 0 & 0,0 \\
\hline Tgl lahir & 57 & 100 & 0 & 0,0 & 0 & 0,0 \\
\hline Jenis Kelamin & 57 & 100 & 0 & 0,0 & 0 & 0,0 \\
\hline Nama Ibu & 56 & 98,2 & 0 & 0,0 & 1 & 1,8 \\
\hline Alamat & 57 & 100 & 0 & 0,0 & 0 & 0,0 \\
\hline Buku KIA & 45 & 78,9 & 8 & 14,0 & 4 & 7,0 \\
\hline Berat Badan & 44 & 77,2 & 10 & 17,5 & 3 & 5,3 \\
\hline Kondisi saat lahir & 57 & 0 & 0 & 0,0 & 0 & 0,0 \\
\hline KN 1 & 34 & 59,6 & 18 & 31,6 & 5 & 8,8 \\
\hline $\mathrm{KN} 2$ & 36 & 63,2 & 16 & 28,1 & 5 & 8,8 \\
\hline KN3 & 34 & 59,6 & 18 & 31,6 & 5 & 8,8 \\
\hline Kunjungan Bayi 1 & 11 & 19,3 & 46 & 80,7 & 0 & 0,0 \\
\hline Bayi 2 & 10 & 17,5 & 47 & 82,5 & 0 & 0,0 \\
\hline Bayi 3 & 10 & 17,5 & 47 & 82,5 & 0 & 0,0 \\
\hline Bayi 4 & 10 & 17,5 & 47 & 82,5 & 0 & 0,0 \\
\hline Bayi 5 & 10 & 17,5 & 47 & 82,5 & 0 & 0,0 \\
\hline Bayi 6 & 10 & 17,5 & 47 & 82,5 & 0 & 0,0 \\
\hline Bayi 7 & 10 & 17,5 & 47 & 82,5 & 0 & 0,0 \\
\hline Bayi 8 & 10 & 17,5 & 47 & 82,5 & 0 & 0,0 \\
\hline Bayi 9 & 10 & 17,5 & 47 & 82,5 & 0 & 0,0 \\
\hline Bayi 10 & 10 & 17,5 & 47 & 82,5 & 0 & 0,0 \\
\hline Bayi 11 & 10 & 17,5 & 47 & 82,5 & 0 & 0,0 \\
\hline Bayi 12 & 10 & 17,5 & 47 & 82,5 & 0 & 0,0 \\
\hline Vit A & 8 & 14,0 & 17 & 29,8 & 32 & 56,1 \\
\hline $\mathrm{Hb} 0$ & 44 & 77,2 & 13 & 22,8 & 0 & 0,0 \\
\hline BCG & 44 & 77,2 & 13 & 22,8 & 0 & 0,0 \\
\hline $\mathrm{P} 1$ & 41 & 71,9 & 16 & 28,1 & 0 & 0,0 \\
\hline $\mathrm{P} 2$ & 35 & 61,4 & 22 & 38,6 & 0 & 0,0 \\
\hline P3 & 29 & 50,9 & 28 & 49,1 & 0 & 0,0 \\
\hline Campak & 30 & 52,6 & 27 & 47,4 & 0 & 0,0 \\
\hline Kematian & 1 & 1,8 & 0 & 0,0 & 56 & 98,2 \\
\hline Masuk balita & 12 & 21,1 & 2 & 3,5 & 43 & 75,4 \\
\hline Keterangan & 5 & 8,8 & 5 & 8,8 & 47 & 82,5 \\
\hline
\end{tabular}


Berdasarkan tabel di atas menunjukkan item dalam kohort bayi diisi dengan lengkap sebesar 16,7\% (No.urut, nama bayi, jenis kelamin, jenis kelamin, alamat, dan kondisi saat lahir). Hasil tidak lengkap_paling sering ditemui pada item NIK (93\%), kematian $(98,2 \%)$, masuk balita $(75,4 \%)$, dan keterangan $(82,5 \%)$. Hal tersebut menunjukkan bahwa sebagian besar item dalam instrumen kohort bayi belum diisi secara lengkap. Hal tersebut dapat terjadi dikarenakan jumlah item yang cukup banyak yaitu sebanyak 47 item, hal ini sejalan dengan hasil penelitian Wijayanti (2016) bahwa banyaknya variabel, formulir dan laporan yang harus dilengkapi oleh Bidan desa menguras waktu, tenaga dan pikiran bidan.

Kelengkapan dalam pengisian kohort bayi menunjukkan keakuratan dalam pencatatan. Pencataan yang kurang lengkap tersebut menunjukkan akurasi dalam pendokumentasian yang kurang. Sunarwan dkk (2012) menyatakan bahwa bidan melakukan pencatatan/ pendokumentasian data PWS KIA masih belum akurat dikarenakan masih menggunakan laporan manual, kurang teliti dan belum paham kriteria yang digunakan dalam indikator pelayanan kegiatan KIA.

Hasil di lapangan didapatkan bahwa instrumen kohort bayi tumpang tindih dengan instrumen kohort balita, sehingga seringkali bidan hanya memasukkan data pada salah satu kohort saja. Hal ini juga dikarenakan persepsi yang berbeda antar bidan terkait dengan cara pengisian kohort bayi.

Hasil penelitian Dharmawan, dkk (2015) menunjukkan bahwa kelengkapan dokumen pencatatan PWS KIA yang terbesar pada Kohort dan Buku KIA $(100 \%)$. Rata-rata kelengkapan data sebesar $50 \%$. Keakurasian data rata rata $70 \%$. Ketepatan waktu pelaporan rata rata sebesar $80 \%$. Skor Rata rata kualitas data sebesar $66,9 \%$. Hasil tabulasi silang menunjukkan bahwa prosentase besar kualitas data PWS yang baik, ditunjukkan dengan prosentase yang besar pada persepsi fasilitas dan motivasi yang baik, beban kerja yang ringan dan masa kerja yang lama. Berdasarkan hasil penelitian tersebut dapat disimpulkan bahwa ketidaktepatan dan ketidaklengkapan dalam pengisian kohort dapat disebabkan oleh beban kerja bidan, masa kerja bidan, persepsi fasilitas dan motivasi bidan.

Rani dan Hargono (2012) dalam penelitiannya menyebutkan bahwa Bidan Desa beranggapan semua formulir pemantauan kesehatan ibu pada PWS KIA mudah untuk dilakukan pengisian, akan tetapi mereka juga menyatakan bahwa jenis formulir yang harus diisikan terlalu banyak, sedangkan beban kerja pelayanan yang tinggi, sehingga tidak dapat melakukan baik pelayanan maupun pencatatan dengan maksimal pada semua formulir. Beban kerja Bidan Desa selama ini berdasarkan hasil observasi memang cukup tinggi, yaitu pelayanan di Puskesmas/ Puskesmas Pembantu, Posyandu, piket di Ruang Bersalin, kegiatan imunisasi, kegiatan kesehatan lingkungan, kegiatan pelaksana program P2, kunjungan rumah, dan pelayanan $\mathrm{KB}$.

\section{SIMPULAN DAN SARAN}

\section{Simpulan}

Sebagian besar $(83,3 \%)$ item dalam kohort bayi belum diisi dengan lengkap oleh bidan, dan hanya sebagian kecil $(16,7 \%)$ diisi dengan lengkap. 


\section{Saran}

Bagi bidan diharapkan lebih meningkatkan dan mempertahankan kualitas dalam pencatatan kohort, agar dapat membantu mendeteksi dan mencegah terjadinya resiko dan komplikasi pada bayi. Bagi puskesmas hendaknya dapat melakukan monitoring dan evaluasi tingkat internal secara berkala pada programprogram Kesehatan Ibu dan Anak, agar terkait dengan pelaksanaan pencatatan/pendokumentasian dapat terlaksana dengan baik, dan bagi Dinas Kesehatan diharapkan dapat melakukan sosialisasi secara berkala pada bidan puskesmas tentang pengisian kohort, selain itu untuk kembali mempertimbangkan format isian kohort bayi agar dapat dipersingkat sehingga dalam pengisian kohort bayi bidan dapat mengisi dengan tepat dan mudah (efektif dan efisien).

\section{DAFTAR PUSTAKA}

Dinas Kesehatan Kabupaten Pekalongan. 2016. Profil kesehatan Kabupaten Pekalongan Tahun 2016. Pekalongan: Dinas Kesehatan Kabupaten Pekalongan.

Dharmawan, Y.,Wigati, PA., Dwijayanti,F. 2012. Kinerja Petugas Dalam Pencatatan Dan Pelaporan PWS KIA Di Puskesmas Duren. Jurnal Kesehatan Masyarakat. Vol. 10 no. 2 Hal. 210-217 https://journal.unnes.ac.id/nju/index.php/kemas

Hastono. 2001. Analisa Data. FKM-UI: Jakarta.

Hani, U., Kusbandiyah, J., Marjati, Yulifah, R. 2010.Asuhan Kebidanan Pada Kehamilan Fisiologis. Jakarta: Salemba Medika

Hidayat, A. \& Aziz A. (2009). Dokumentasi Kebidanan. Jakarta: Fitramaya

Jannah, N. 2011.Buku Ajar Asuhan Kebidanan : Kehamilan. Yogyakarta : Penerbit ANDI.

Kareth. Y., Purnami. CT., Sriatmi. A. 2015. Evaluasi Pelaksanaan Pencatatan dan Pelaporan Pelayanan Kia oleh Bidan diPuskesmas Kabupaten Nabire, Provinsi Papua (Studi Kasus di PuskesmasDistrik Nabire). Jurnal manajemen kesehatan Indonesia. Vol.3.no 1. Hal. 34-43.

Kementrian Kesehatan RI. (2009). Pedoman Pemantauan Wilayah Setempat Kesehatan Ibu dan Anak (PWS-KIA). Jakarta

Manuaba, I.B.G. 2008.Ilmu Kebidanan Kandungan dan KB.Jakarta : EGC

Nugroho, T. dan Utama B.I., 2014. Masalah Kesehatan Reproduksi Wanita.Yogyakarta : Nuha Medika.

Nursalam. 2009. Keperawatan Kesehatan Komunitas. Jakarta : PT. Salemba Medika.

Prawirohardjo, S. 2006. Pelayanan Kesehatan Maternal dan Neonata.Jakarta : $\mathrm{YBP}-\mathrm{SP}$

2009. Ilmu Kebidanan. Jakarta: PT Bina Pustaka

Rani, I.A. \& Arif H..2013. Deskripsi Pencatatan Dan Pelaporan Pemantauan Kesehatan Ibu Pada PWS-KIA Berdasarkan Atribut Surveilan. Jurnal Berkala Epidemiologi, Vol. 1, No. 2 September 2013: 302315.journal.unair.ac.id/download-fullpapers-jbe02bfb2e278full.pdf diakses pada tanggal 10 Februari 2017 
Jurnal Kebidanan Indonesia. Vol 10 No 2. Juli 2019 (76-82)

Saifuddin, A.B. 2009. Panduan Praktis Pelayanan Kesehatan Maternal dan Neonatal. Jakarta: EGC.

Syahlan, J.H. 1996. Kebidanan Komunitas. Jakarta: Yayasan Bina Sumber Daya Kesehatan.

Wijayanti, B. 2015. Evaluasi pemantauan kesehatan anak pada Pemantauan Wilayah Setempat Kesehatan Ibu dan Anak (PWS KIA) berdasarkan atribut surveilans di Puskesmas Ranuyoso Kabupaten Lumajang. Skripsi. Surabaya, Universitas Airlangga: 52-117 